\title{
RANCANG BANGUN DATA MART POINT KEAKTIFAN MAHAHASISWA PADA UNIVERSITAS
}

\author{
Gabriel Geovan Ocnota ${ }^{1)}$ Hendro Poerbo ${ }^{2)}$ \\ ${ }^{1)}$ Sistem Informasi Universitas Machung, Villa Puncak Tidar N-1 Malang \\ email :321510013@student.machung.ac.id ${ }^{1}$,hendro.poerbo@machung.ac.id ${ }^{2}{ }^{3}$
}

\begin{abstract}
Abstraksi
Universitas Ma Chung merupakan Universitas Swasta di Malang, Jawa Timur yang memiliki banyak data, salah satunya adalah data point keaktifan mahasiswa. Universitas Ma Chung masih belum memiliki database khusus yang berfungsi sebagai data warehouse, perusahaan hanya memiliki database operasional sehingga untuk melakukan analisis data kurang optimal dan memerlukan banyak waktu.

Tujuan dari dilaksanakannya penelitian ini adalah merancang dan membangun data mart yang dapat digunakan untuk menampilkan laporan grafik point keaktifan mahasiswa pada Universitas Ma Chung menggunakan SSRS (SQL Server Reporting Services), sehingga universitas dapat melakukan analisis data secara optimal dan memiliki laporan informasi eksekutif. Metode penelitian yang digunakan adalah analisa dan perancangan, dimana pada tahap analisa melakukan pengumpulan data dan membuat instrumen perancangan. Sedangkan tahap perancangan menggunakan Kimball lifecycle dan 9-step data warehouse design methodology. Hasil yang diperoleh dari penelitian ini adalah skema snowflake pada data mart, ETL harian otomatis, dimana data dikonversi dari SQL Server (database transaksional) ke dalam SQL Server (database tujuan), OLTP, OLAP (cube) dan reporting berbasis web. Simpulan dari penelitian ini adalah rancangan data mart point keaktifan mahasiswa yang dapat digunakan untuk menyimpan data historis point keaktifan mahasiswa pada Universitas Ma Chung sehingga dapat digunakan untuk analisis bisnis lebih lanjut.
\end{abstract}

\section{Kata Kunci :}

Perancangan, ETL, Cube, SSRS, Data Mart.

\begin{abstract}
Ma Chung University is a Private University in Malang, East Java, that has a lot of data, one of which is student activity data points. Ma Chung University still does not have a special database that functions as a data warehouse, the company only has an operational database so that data analysis is not optimal and requires a lot of time.

The purpose of this research is to design and build a data mart that can be used to display student activeness point graph reports at Ma Chung University using SSRS (SQL Server Reporting Services), so that the university can perform data analysis optimally and have executive information reports. The research method used is analysis and design, where at the analysis stage data collection and design instruments are made. While the design phase uses Kimball Lifecycle and 9-step data warehouse design methodology.

The results obtained from this study are the snowflake scheme on the data mart, automatically daily ETL, data converted from SQL Server (transactional database) into SQL Server (destination database), OLTP, OLAP (cube) and web-based reporting. The conclusion of this study is the design of student activeness data mart points that can be used to store historical data on student activity points at Ma Chung University so that they can be used for further business analysis.
\end{abstract}

\section{Keywords :}

Design, ETL, Cube, SSRS, Data Mart.

\section{PENDAHULUAN}

Universitas Ma Chung merupakan salah satu Universitas swasta di kota Malang, Jawa Timur yang diresmikan tahun 2007 dan meluluskan wisudawan-wisudawati terbaik dengan kompetensi unggul baik dalam kegiatan akademik maupun dalam kegiatan non akademik. 
Dalam menunjang kegiatan non akademik, Universitas Ma Chung mendorong setiap mahasiswanya untuk berperan aktif dalam mengikuti kegiatan, sehingga dibuatlah sebuah sistem point keaktifan mahasiswa yang membantu Universitas Ma Chung untuk meningkatkan kegiatan non akademik tersebut.

Hingga saat ini, Universitas Ma Chung masih belum mempunyai penyimpanan khusus yang digunakan untuk mengelola data point keaktifan mahasiswa, dimana dengan adanya penyimpanan dan pengelolaan data khusus tersebut, bisa memudahkan pihak Universitas untuk merekap data point keaktifan untuk membuat laporan harian, mingguan, bulanan, triwulan, kuartal, semester maupun tahunan. Selain itu, Universitas Ma Chung sudah beroperasi sangat lama, data poin keaktifan pun sangatlah banyak, sehingga jika pihak manajemen ingin melihat perkembangan ataupun keadaan data berdasarkan periode tertentu, laporan tersebut akan sangat sulit dibuat dan memerlukan waktu yang sangat lama. Dari halhal tersebut dapat menjadikan permasalahan yang besar terhadap proses bisnis point keaktifan mahasiswa di Universitas Ma Chung, sehingga hal tersebut diangkat menjadi topik permasalahan yang akan dibahas pada laporan Tugas Akhir ini.

Sesuai dengan akar dari permasalahan hingga akibat-akibat yang ditimbulkan maka solusi yang diambil agar proses pengelolaan data point keaktifan mahasiswa di Universitas Ma Chung dapat berjalan lancar, mudah dan cepat adalah membangun sebuah rancang bangun data mart Universitas Ma Chung yang mengelola data Point Keaktifan Mahasiswa. Rancang bangun data mart yang akan dibangun menggunakan aplikasi tools Power Designer, SQL Server (Management Studio), Visual Studio dan SRSS (SQL Server Reporting Services) dengan menggunakan metode Kimball Lifecycle.

Dengan adanya perancangan data mart ini, data point keaktifan mahasiswa dapat diintegrasikan ke suatu tempat penyimpanan yang akan memberikan kemudahan bagi pemakai untuk memperoleh Informasi dan dapat membantu para eksekutif untuk mengevaluasi dan menganalisis dari hasil yang telah didapatkan.

\section{METODE / ALGORITMA}

Metode penelitian yang digunakan dalam pengembangan Rancang Bangun Data Mart Point Keaktifan Mahasiswa Universitas Ma Chung ini adalah menggunakan tahapan pengerjaan Kimball Lifecycle, dimana dalam mengembangkan data mart, tahapan pengerjaan Kimball Lifecycle memiliki tahap yang lengkap dan rinci untuk merancang dan membangun data mart, 
URL : https://jurnal.machung.ac.id/index.php/kurawal

sehingga hasil yang didapatkan akan akurat. Pengembangan dibagi dalam tahap-tahap yang ditentukan yaitu project planning, bussines requirement definition, technology track, data track, bussiness intelligence track, deployment dan maintenance \& growth, sedangkan pada tahap data track (dimensionality modelling) metode perancangan data mart yang digunakan adalah menggunakan metode nine-step methodology.

Tabel 1 Metode Pengerjaan Kimball Lifecycle

\begin{tabular}{|c|c|c|}
\hline Nama & Kegiatan & Cara/Tools \\
\hline Project Planning & $\begin{array}{l}\text { - Pengumpulan data } \\
\text { - Instrumen Perancangan }\end{array}$ & $\begin{array}{l}\text { - Melakukan pengumpulan data Point } \\
\text { Keaktifan Mahasiswa yang didapat dari } \\
\text { Unit Pelaksana Teknis dan melakukan } \\
\text { survei terhadap sistem Macsys Universitas } \\
\text { Ma Chung } \\
\text { - Melakukan penyusunan instrumen untuk } \\
\text { merancang dan mengembangkan sistem } \\
\text { Data Mart. }\end{array}$ \\
\hline $\begin{array}{l}\text { Bussiness } \\
\text { Requirement } \\
\text { Definition }\end{array}$ & - Analisa Proses Bisnis & $\begin{array}{l}\text { - Analisa Profil universitas, analisa } \\
\text { kebutuhan, analisa alur bisnis, analisa } \\
\text { permasalahan yang dihadapi dan usulan } \\
\text { pemecahan masalah). } \\
\text { - Wawancara kepada BKPKK }\end{array}$ \\
\hline Technology Track & $\begin{array}{l}\text { - Specific Requirements } \\
\text { - Analisa ERD } \\
\text { - Kamus data } \\
\text { - Arsitektur Data Mart } \\
\text { - Desain Dashboard }\end{array}$ & $\begin{array}{l}\text { - Membuat Specific Requirements } \\
\text { - Membuat ERD } \\
\text { - Membuat Kamus Data } \\
\text { - Membuat Arsitektur Teknologi } \\
\text { - Membuat desain mockup dashboard }\end{array}$ \\
\hline Data Track & $\begin{array}{l}\text {-Dimensionality Modelling } \\
\text { menggunakan metode Nine-step } \\
\text { methodology } \\
\text { - Physical Design } \\
\text {-Hasil dan desain ETL (extract, } \\
\text { transform, loading) } \\
\text { - ETL Scheduling }\end{array}$ & $\begin{array}{l}\text { - Melakukan analisa perancangan data mart } \\
\text { menggunakan metode nine-step } \\
\text { methodology. } \\
\text { - Pembuatan conceptual data model dan } \\
\text { mengubahnya menjadi physical data } \\
\text { model } \\
\text { - ETL (Extract, Transform, Loading) } \\
\text { - ETL Scheduling (Job) }\end{array}$ \\
\hline $\begin{array}{l}\text { Bussiness } \\
\text { Intelligence Track }\end{array}$ & $\begin{array}{l}\text {-Proses Pembuatan Cube \& } \\
\text { Reporting } \\
\text { - Cube Scheduling }\end{array}$ & $\begin{array}{l}\text { - Membuat web reporting hasil cube yang telah } \\
\text { dibuat. } \\
\text { - Penjadwalan proses pengolahan cube }\end{array}$ \\
\hline
\end{tabular}


URL : https://jurnal.machung.ac.id/index.php/kurawal

Tabel 1 Metode Pengerjaan Kimball Lifecycle Lanjutan

\begin{tabular}{|l|l|l|}
\hline Deployment & -Uji Coba proyek & $\begin{array}{l}\text { - Uji coba terhadap proyek data mart yang } \\
\text { telah selesai dibuat pada SSRS (SQL } \\
\text { Server Reporting Services) dengan } \\
\text { tampilan web. }\end{array}$ \\
\hline $\begin{array}{l}\text { Maintenance \& } \\
\text { Growth }\end{array}$ & $\begin{array}{l}\text {-Perawatan \& Pengembangan } \\
\text { Proyek }\end{array}$ & $\begin{array}{l}\text { - Melakukan perawatan dan pengembangan } \\
\text { terhadap data mart }\end{array}$ \\
\hline
\end{tabular}

\subsection{Project Planning}

Project Planning adalah fase dasar atau proses dasar dari manajemen untuk menetapkan tujuan dan langkah-langkah yang harus dilakukan agar tujuan tercapai. Tahap Project Planning bertujuan untuk memberikan informasi untuk mengkoordinasikan pekerjaan agar menghasilkan pekerjaan yang akurat dan efektif. Pada proses pembangunan dan pengembangan project data mart point keaktifan mahasiswa pada Universitas Ma Chung, tahap project planning dimulai dengan melakukan pengumpulan data dan penyusunan instrumen perancangan.

\subsection{Bussiness Requirement Definition}

Bussiness Requirement Definition mencakup bagaimana suatu Universitas mencapai tujuan mereka, dan mendefinisikan kapabilitas untuk menyediakan layanan kepada para pemangku kepentingan eksternal. Bussiness Requirement akan mempengaruhi seluruh keputusan dari hulu sampai hilir pengembangan proyek. Poin terpenting dari proses ini adalah mencari faktor kunci yang diperlukan oleh bisnis, baik saat ini maupun di masa mendatang. Dalam tahap Bussiness Requirement Definition akan menjelaskan profil Universitas, alur proses bisnis, permasalahan yang dihadapi dan usulan pemecahan masalah. 
URL : https://jurnal.machung.ac.id/index.php/kurawal
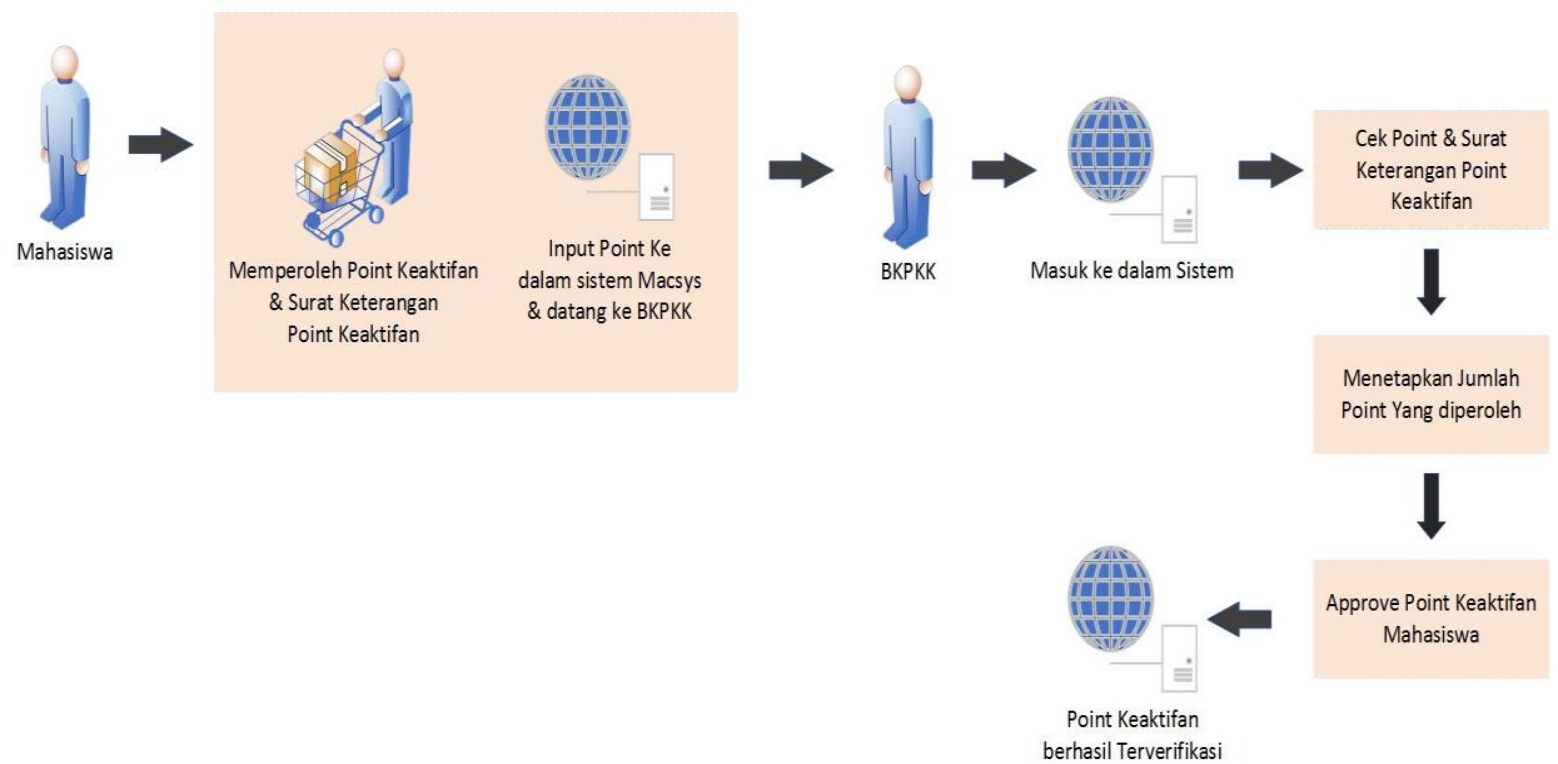

Gambar 1 Alur Proses Bisnis Point Keaktifan Mahasiswa Universitas Ma Chung

\subsection{Technology Track}

Pada tahap ini dimulai dengan desain arsitektur sistem untuk membuat daftar kebutuhan teknologi. Berikut Penjelasan mengenai bagian arsitektur teknologi data mart point keaktifan mahasiswa pada Universitas Ma Chung dijelaskan menurut peran dari setiap bagian didalamnya.

1. Mahasiswa : bertanggung jawab terhadap data point keaktifan mahasiswa yang telah diperoleh.

2. BKPKK(Biro Kemahasiswaan, Pendidikan Karakter \& Kepemimpinan) : bertanggung jawab melakukan monitoring dan melakukan approve terhadap point keaktifan mahasiwa.

3. (UPT) Unit Pelaksana Teknis : bertanggung jawab untuk menginput data point keaktifan mahasiswa ke dalam data mart.

4. Data Mart : berfungsi sebagai media penyimpanan data point keaktifan Mahasiswa yang sudah di transformasi oleh Unit Pelaksana Teknis.

5. Laporan Data Tabel dan Grafik Point Keaktifan Mahasiswa : merupakan output dari data mart yang dapat diubah sesuai kebutuhan. 


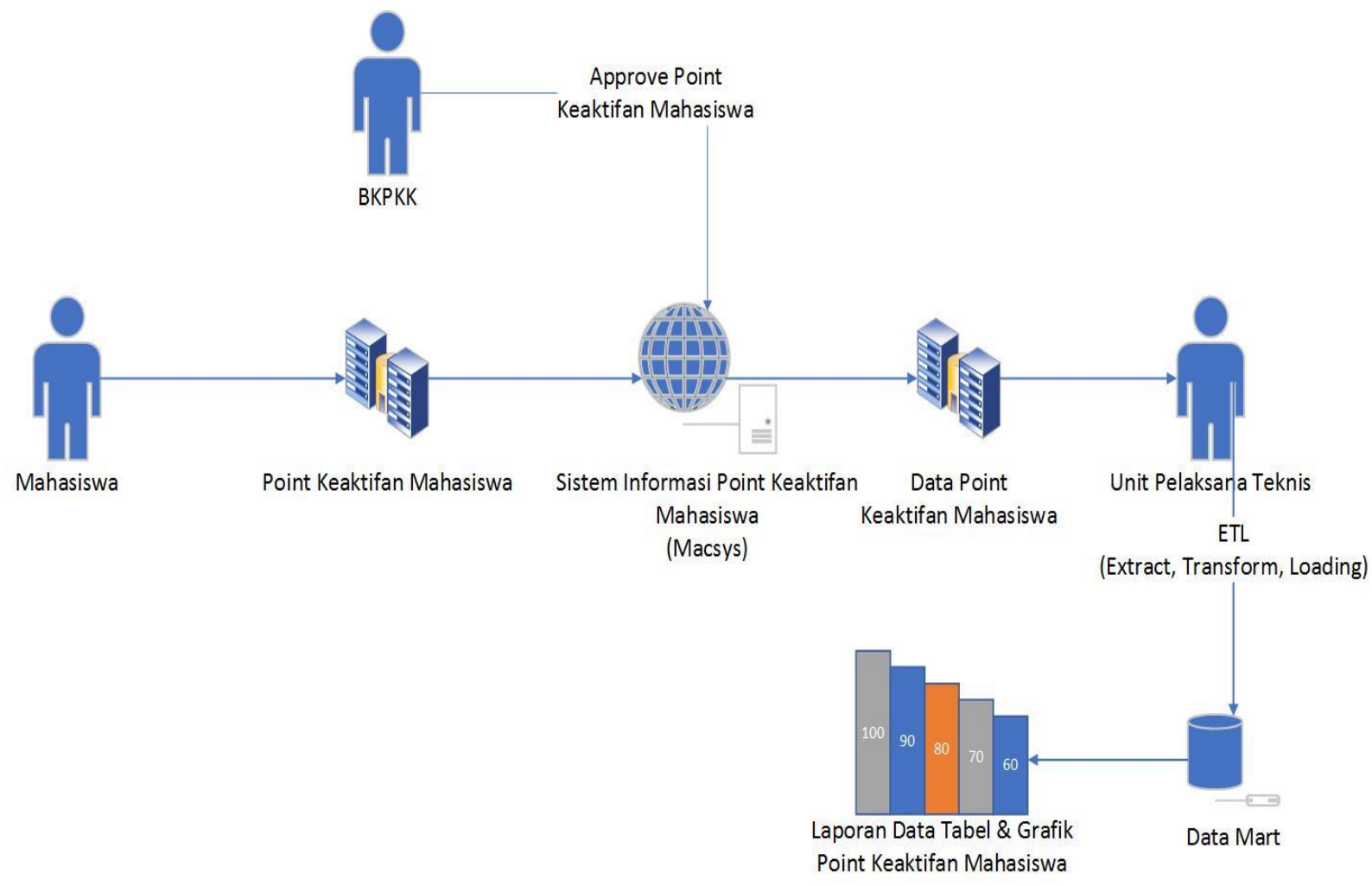

Gambar 2 Arsitektur Data Mart Point Keaktifan Mahasiswa Universitas Ma Chung

\subsection{Data Track}

Pada bagian tahap ini akan menggunakan metode nine-step methodology yang terdiri dari tahap memilih pemilihan proses, pemilihan grain, identifikasi dan penyesuaian dimensi, pemilihan fakta, penyimpanan pre-calculation dalam tabel fakta, pelengkapan pada tabel dimensi, memilih durasi database dan melacak dimensi yang berubah secara perlahan yang akhirnya akan menghasilkan proses ETL (Extract, Transform, Loading).

1. Memilih Proses

Data yang digunakan adalah data fakultas, prodi, asal sekolah, biodata mahasiswa, detail nim mahasiswa, rumpun, kegiatan, jabatan kegiatan, ruang lingkup, approval, kota, status mahasiswa dan waktu.

2. Memilih Grain

Analisis yang dapat dilakukan adalah point fakultas yang paling banyak, point prodi yang paling banyak, point tahun angkatan mahasiswa yang paling banyak, point asal sekolah mahasiswa yang paling banyak, point asal kota mahasiswa yang paling banyak, point status mahasiswa yang paling banyak, rumpun point yang paling banyak terpilih, jabatan kegiatan yang paling banyak terpilih, ruang lingkup point yang paling 
banyak terpilih, transaksi point mahasiswa menurut status approval (disetujui/belum disetujui), jumlah point akhir mahasiswa dan jumlah transaksi input point mahasiswa.

3. Identifikasi Dimensi

Dimensi yang sesuai untuk membuat data mart point keaktifan mahasiswa adalah dimensi waktu, fakultas, prodi, asal sekolah, biodata mahasiswa, detail nim mahasiswa, rumpun, kegiatan, jabatan kegiatan, ruang lingkup, approval, kota dan status mahasiswa.

4. Identifikasi Fakta

Point fakultas yang paling banyak, point prodi yang paling banyak, point tahun angkatan mahasiswa yang paling banyak, point asal sekolah mahasiswa yang paling banyak, point asal kota mahasiswa yang paling banyak, point status mahasiswa yang paling banyak, rumpun point yang paling banyak terpilih, jabatan kegiatan yang paling banyak terpilih, ruang lingkup point yang paling banyak terpilih, transaksi point mahasiswa menurut status approval (disetujui/belum disetujui), jumlah point akhir mahasiswa dan jumlah transaksi input point mahasiswa.

5. Menentukan data pre-kalkulasi dari tabel fakta

Data mart memiliki satu tabel fakta yaitu fakta point keaktifan mahasiswa. Dalam tabel fakta tersebut memiliki data yang dikalkulasi terlebih dahulu yang akan diproses saat pembuatan cube berdasarkan waktu (harian, mingguan, bulanan, triwulan, kuartal, semester dan tahunan).

6. Melengkapi Tabel Dimensi

Dimensi waktu (year, half year, quarter, trimester, month, week, day), fakultas (nama_fakultas), prodi (nama_prodi), kota (nama_kota), asal sekolah (nama_sekolah), biodata mahasiswa (nama_mahasiswa), detail nim mahasiswa (nim, tahun_angkatan),status_nim (status_nim), rumpun (deskripsi_rumpun), kegiatan (deskripsi_kegiatan), jabatan kegiatan (deskripsi_jabatan_kegiatan), ruang lingkup (deskripsi_ruang_lingkup), approval (status_approval).

7. Memilih Durasi Basis Data

Pada tahap ini akan melakukan penentuan batasan waktu data yang diambil dan dipindahkan ke dalam data mart. Data yang akan dianalisis pada penelitian ini merupakan data transaksi Point Keaktifan Mahasiswa pada Universitas Ma Chung dari bulan februari 2012 sampai dengan bulan maret 2019. 
8. Melacak Dimensi yang berubah secara perlahan

Tahap ini menentukan bagaimana menangani perubahan data dalam data mart. Terdapat 3 cara untuk menangani perubahan data dalam data mart, yaitu mengganti secara langsung pada tabel dimensi, membentuk record baru untuk setiap perubahan baru, dan perubahan data yang membentuk kolom baru yang berbeda. Peneliti memilih untuk mengganti secara langsung pada tabel dimensi, sehingga tidak ada pemborosan terhadap media penyimpanan data untuk tabel dimensi. 
URL : https://jurnal.machung.ac.id/index.php/kurawal

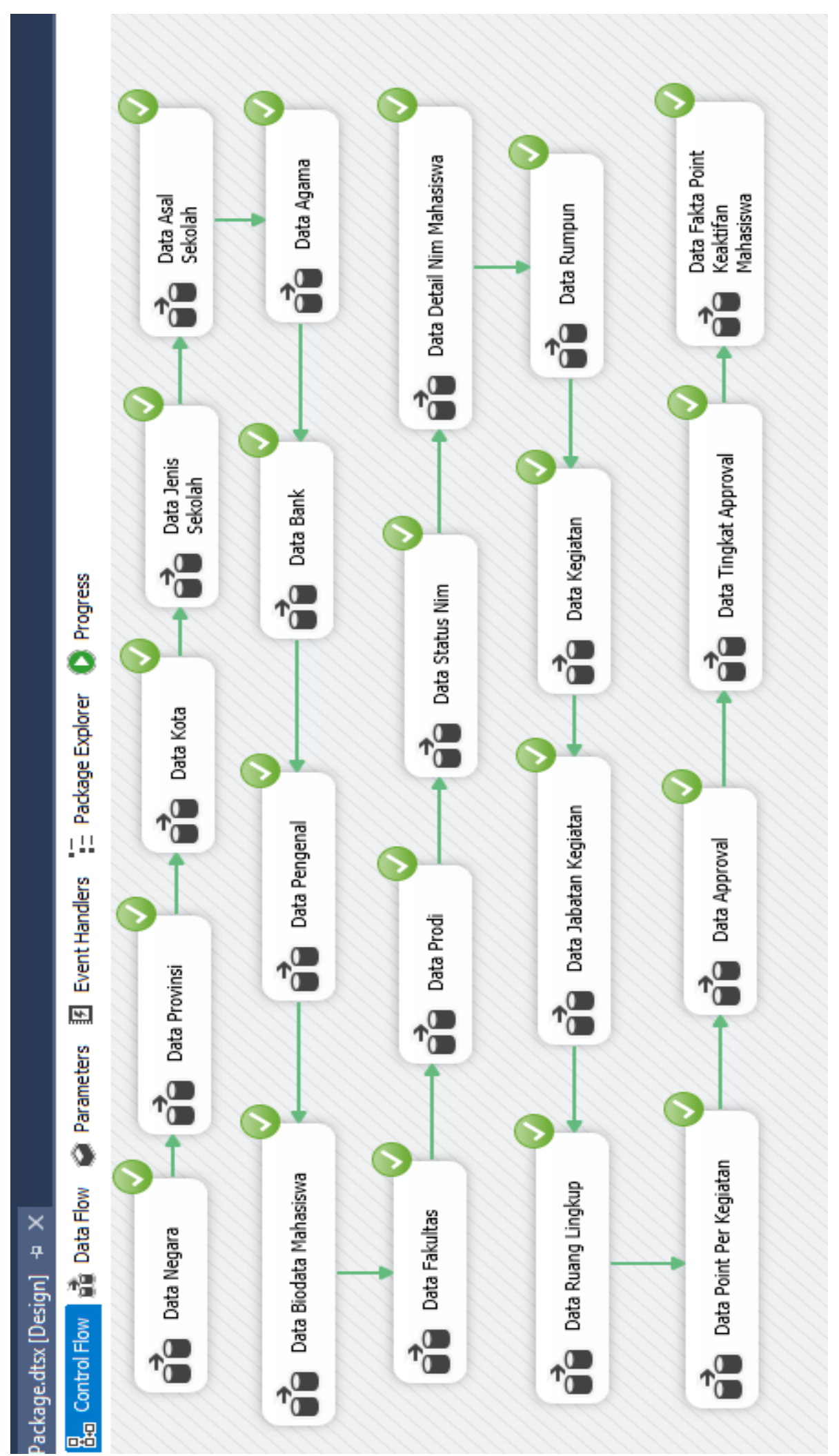

Gambar 3 Proses ETL Point Keaktifan Mahasiswa berhasil dijalankan 
URL : https://jurnal.machung.ac.id/index.php/kurawal

\section{HASIL DAN PEMBAHASAN}

\subsection{Bussiness Intelligence Track}

Pada bab ini akan dibahas mengenai hasil pembangunan data mart pada Point Keaktifan Mahasiswa pada Universitas Ma Chung. Data mart nantinya digunakan untuk menganalisa point keaktifan mahasiswa Universitas Ma Chung. Hasil yang akan dibahas adalah proses pembuatan cube dan hasil penyajian laporan data mart pada Point Keaktifan Mahasiswa pada Universitas Ma Chung.

\subsection{Deployment}

Setelah berhasil menjalankan proses ETL dan Cube pada Data Mart, langkah yang terakhir yang harus dibuat adalah membuat pelaporan data mart point keaktifan mahasiswa. Tools yang digunakan pada proses pembuatan reporting adalah SQL Server Reporting Services. Berikut merupakan hasil reporting yang berhasil dibuat.

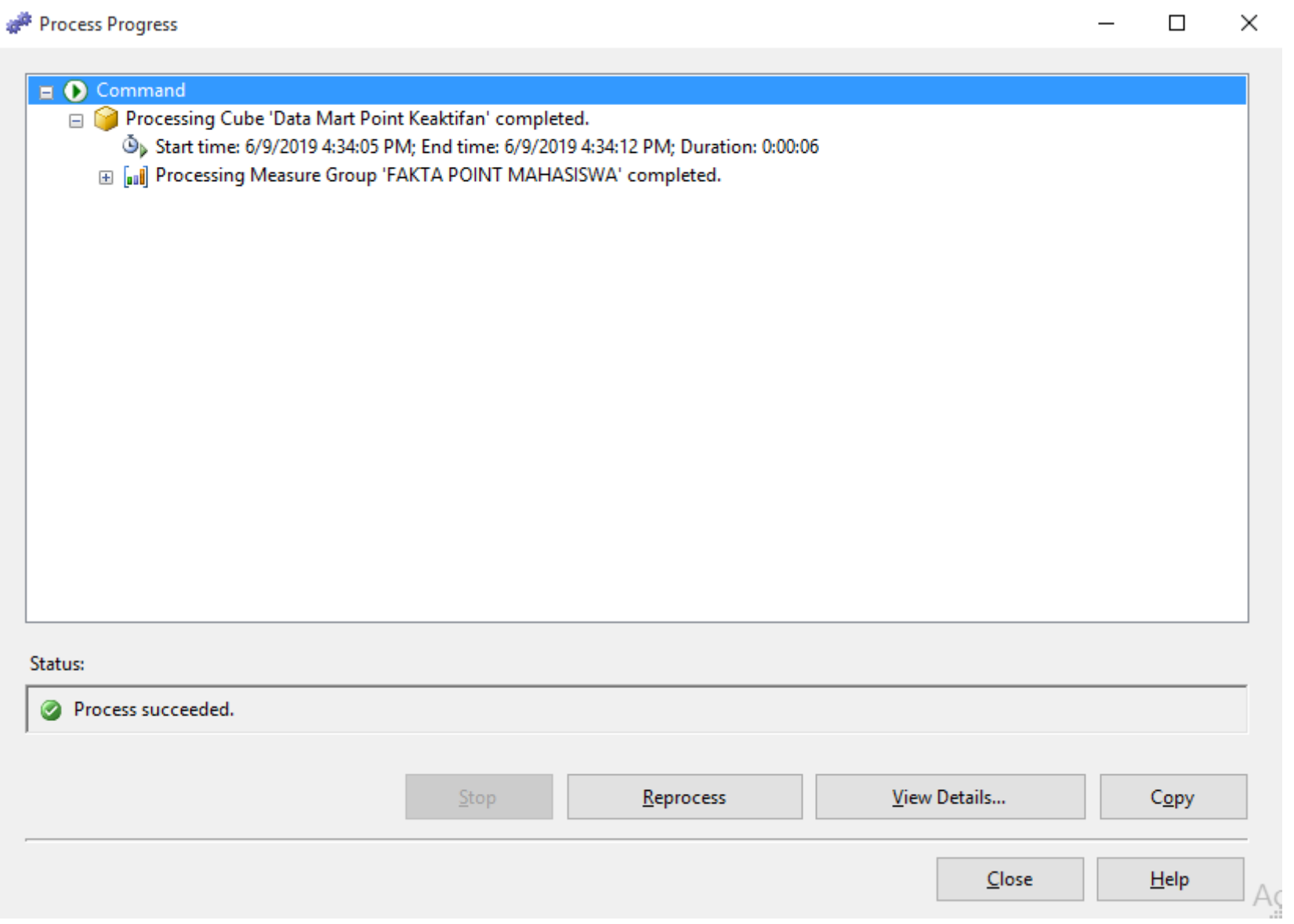




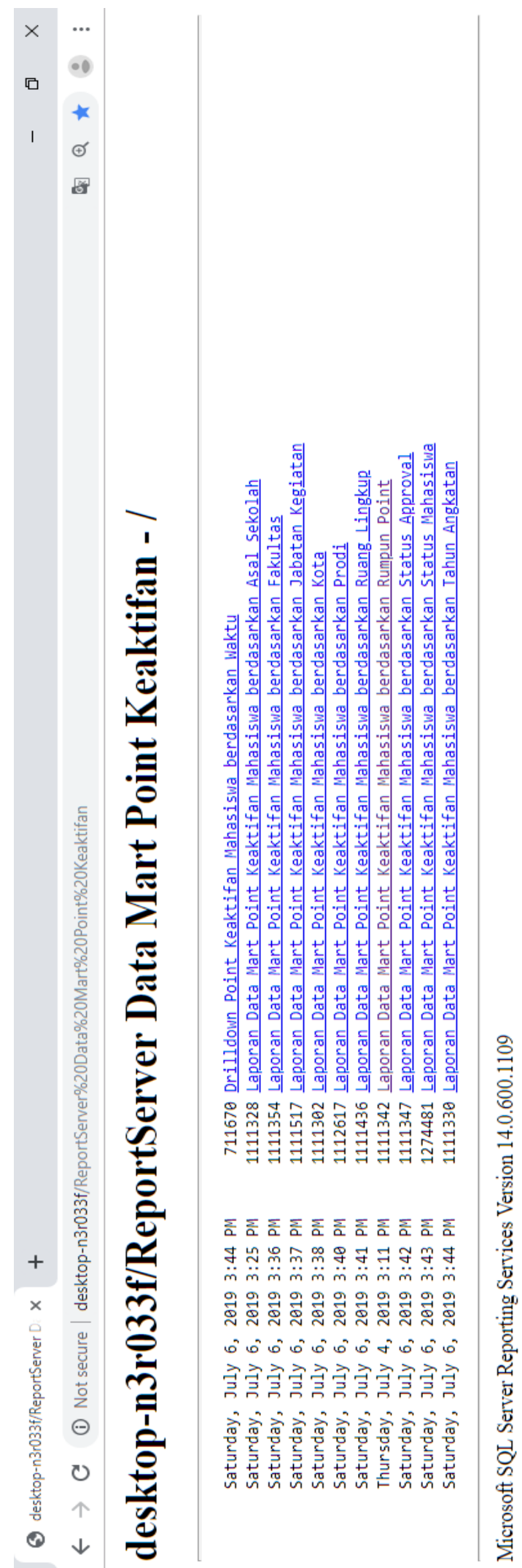

Gambar 5 Tampilan pilihan report 
URL : https://jurnal.machung.ac.id/index.php/kurawal

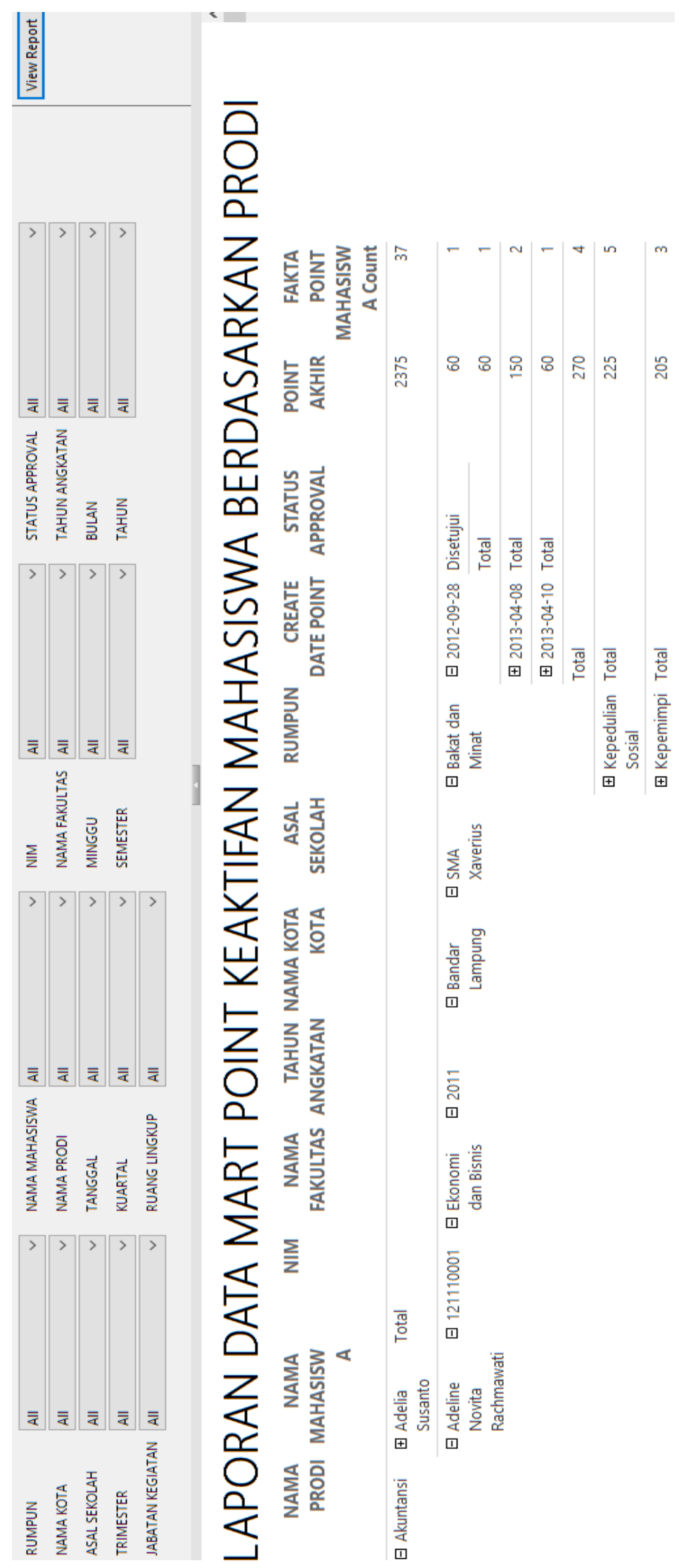

Gambar 6 Tampilan Laporan Point Keaktifan Mahasiswa 


\section{KESIMPULAN}

Rancangan data mart point keaktifan mahasiswa dapat digunakan untuk menyimpan data historis bagian point keaktifan pada Universitas Ma Chung yang dapat digunakan untuk analisis lebih lanjut. Data mart nantinya digunakan oleh pemimpin dan pihak eksekutif bagian point keaktifan mahasiswa (Biro Kemahasiswaan, Pendidikan Karakter \& Kepemimpinan) sebagai alat pembantu menyerap dan menganalisis informasi tentang point keaktifan mahasiswa serta pembuatan keputusan di masa mendatang. Dengan adanya data mart, laporan yang dihasilkan bisa dilihat dengan berbagai sudut pandang. Penyajian laporan point keaktifan mahasiswa juga dapat dibuat dengan lebih cepat dan memiliki tampilan yang menarik dan informatif dalam bentuk grafik yang bisa diakses dengan browser.

Diharapkan Data mart dapat diintegrasikan dengan data Universitas bagian yang lain agar data dan informasi yang dihasilkan lebih akurat dan kompleks, seperti data pada bagian human resources, keuangan, perpustakaan, administrasi , serta data non akademik lainnya, sehingga menjadi sebuah enterprise data warehouse.

\section{DAFTAR PUSTAKA}

[1] Connolly, T., Begg, 2015, Database Systems: a practical approach to design, Implementation, and management, Pearson Education, America.

[2] Kimball Ralph \& Joe Caserta, 2014, The Data Warehouse ETL Toolkit, Wiley and Sons, Indianapolis.

[3] Inmon, W.H., 2014, Building the Data Warehouse $3^{\text {rd }}$ Edition, John Wiley \& Sons Inc, Canada.

[4] Indrajani, 2015, Database Design (Case Study All in One), PT Elex Media Komputindo, Jakarta.

[5] Al-Bahra Bin Ladjamudin, 2014, Analisis dan Desain Sistem Informasi, Graha Ilmu, Yogyakarta.

[6] Kimball Ralph \& M. Ross, 2015, The Kimball Group Reader: Relentlessly Pratical Tools for Data Warehousing and Business Intelligence, Wiley and Sons, Indianapolis.

[7] Turban Efraim \& Linda Volonino, 2015, Information Technology for Management, John Willey \& Sons, Asia. 